\title{
Unemployment and inflation persistence in Spain: Are there Phillips trade-offs?
}

\author{
Juan J. Dolado, ${ }^{1}$ J. David López-Salido ${ }^{2}$, Juan L. Vega ${ }^{3}$ \\ 1 Departamento de Economía, Universidad Carlos III de Madrid, c/ Madrid 126, 28903 Getafe \\ (Madrid), Spain (e-mail: dolado@eco uc3m es) \\ 2 Research Departament, Banco de España, c/ Alcalá 50, 28014 Madrid, Spain (e-mail: davidl@ bde es) \\ 3 Research Department, European Central Bank, Kaisserstraße 29, 60311 Frankfurt, Germany \\ (e-mail: juan_luis vega@ecb int)
}

\begin{abstract}
This paper studies the dynamic behavior of inflation and unemployment in Spain during the period 1964-1997. In particular, we analyze the implications of high persistence in both unemployment and inflation dynamics for inference regarding the size of Phillips trade-offs and sacrifice ratios in the Spanish economy, in response to a demand shock. To do so we use a Stuctural VAR approach with several identification outlines which give rise to alternative interpretations of the joint unemployment-inflation dynamics. When using a bivariate VAR we cannot reject the existence of a permanent output loss of one-half of one percentage point for each percentage point of permanent disinflation. However, when the VAR is augmented with a third variable, in order to disentangle monetary from non-monetary shocks within the demand class, the evidence favours a lower and marginally permanent trade-off with an output loss of about one-fourth of one percentage point.
\end{abstract}

JEL classification: E12, E13, E24, C32

Key words: Phillips trade-offs, sacrifice ratios, vector autoregressions, shocks

\section{Introduction}

The Spanish annual rate of (CPI) inflation came down from $24.6 \%$ in 1977 to about $2 \%$ in 1997, at the time when this paper was written (see Fig. 1). However, the big blot is still unemployment, nowadays slightly down at just under $16 \%$

The views expressed herein are solely those of the authors and thus do not necessarily represent those of the institutions with which they are affiliated We are grateful to Mike Artis, Jim Conklin, Agustin Maravall, Jose Viñals, two anonymous referees and seminar participants at the Banco de España, ESEM 98 (Berlin), and the CEPR Conference on "New Approaches to the Study of Business Cycle Fluctuations" (Madrid) for valuable comments and suggestions 
(the largest among OECD countries). From 1977 to 1989, the unemployment rate jumped from $5.1 \%$ to $17.2 \%$. Throughout the 1990 s it has averaged $20.4 \%$ with a maximum of $24.6 \%$ in the first quarter of 1994 . The fact that the unemployment rate was in 1997 close to what the inflation rate was in 1977 and, conversely, that the inflation rate is only slightly below the unemployment rate in the mid1970s may look at first sight as if the unemployment-inflation trade-off over the sample period was close to $1: 1$. This impression, however, may be deceptive since both variables respond to demand and supply shocks while, in principle, only the former shocks give rise to a genuine trade-off. In this paper we tackle this issue in greater depth.

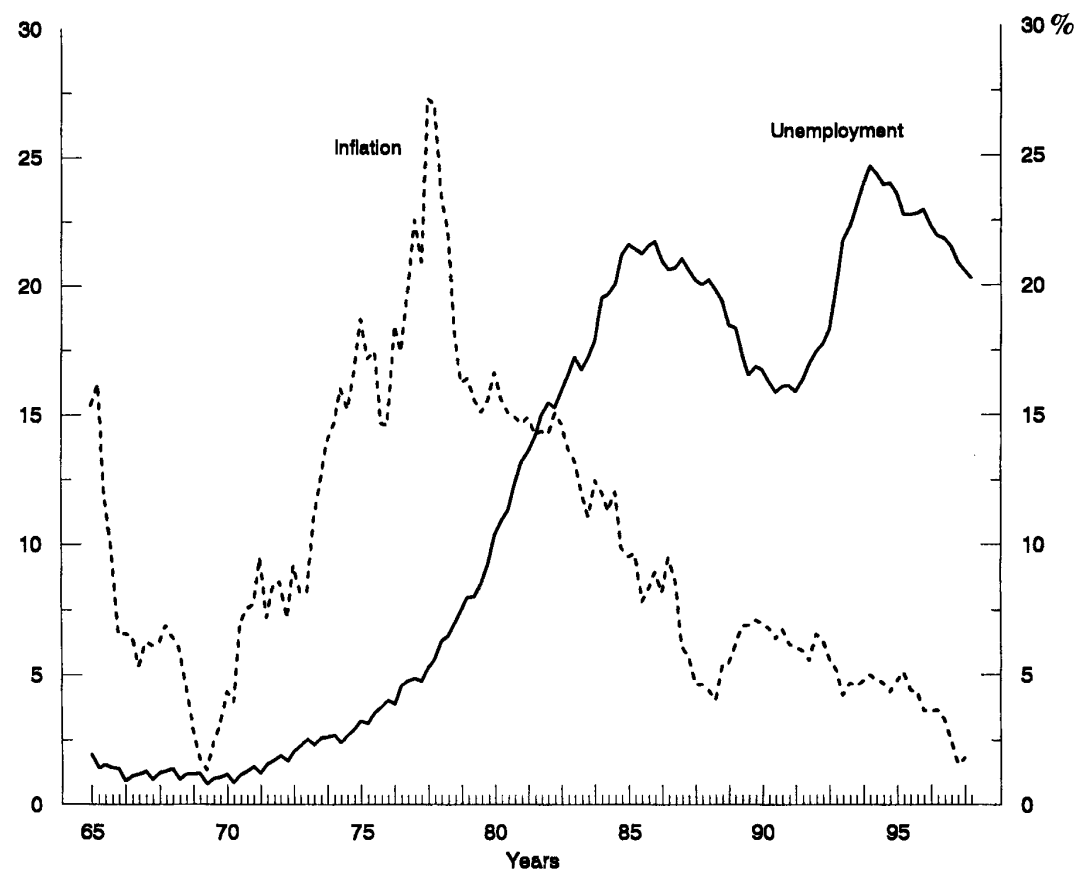

Fig. 1. Inflation and unemployment in Spain

Disentangling the trade-offs implied by those figures is a key issue for judging the performance of the Spanish economy over the last two decades. In this respect, it is noteworthy that several alternative interpretations are compatible with the observed inflation-unemployment correlations. So, e.g., one possible interpretation of the aforesaid episodes could be a keynesian one under which, contractionary aggregate demand policies are a major cause of the high unemployment rate which, in turn, leads later to a fall in inflation and eventually to an output recovery. However, in the presence of important hysteretic mechanisms, the trade-off between unemployment and inflation could be a permanent 
one $^{1}$. Other alternative interpretations, which do not allow for long-run trade-offs, could be related, on the one hand, to the important role played by expectations and credibility-related phenomena (neoclassical-monetarist-rational expectations models) and, on the other hand, to the predominant role played by structural supply-side shocks (real business cycle models); allowing for the latter may even imply the absence of long-run and even short-run trade-offs (see Sargent 1982).

Naturally, these alternative views imply: (i) different roles for the economic shocks leading the sources of business cycle fluctuations and stochastic growth; (ii) different roles for the propagation mechanisms of those shocks; and, (iii) drastic differences for economic policy design. These simple and well-known ideas pose difficulties for the researcher when trying to identify the demand/supply shocks within the bivariate system formed by inflation and unemployment. This is so since alternative identification outlines, corresponding to each of these views, will give rise to the same reduced form, explaining equally well the observed set of dynamic correlations between both variables. Thus, we need some method to distinghish among them.

In this paper we deal with those issues through the analysis of the joint dynamic behaviour of inflation and unemployment in Spain over the period 19641997. Our approach will consist of modelling a Vector Autoregression (VAR) in both variables, conditioning on other exogenous variables, and imposing several identifying restrictions on the VAR innovations in order to recover demand and supply shocks. After all, the idea behind both the unemployment-inflation tradeoff and the sacrifice ratio is to analyse the dynamic responses of both variables to a demand shock. Hence the importance of distinguishing between both types of shock.

Specifically, our approach will be based upon the Structural Vector Autoregression (SVAR) methodology, following an earlier paper by King and Watson (1994). We do this for two reasons. First, because until the beginning of the 1990s, most of the research on the unemployment-inflation trade-off was based upon the estimation of quasi-structural equations relating wage/price-inflation and the unemployment rate, i.e., the so-called Phillips curve approach (see, e.g., Gordon 1970) where many of the relevant variables were treated as exogenous and where dubious identification restrictions and measurement problems abounded (see Manning 1993). And, secondly, because it allows us to gauge how robust some of the results obtained with the previous approach are, under the competing SVAR methodology. Furthermore, as above mentioned, by using the SVAR methodology to map reduced form innovations onto shocks, we will be able to pose a well defined question, namely, What effects will demand shocks have on the levels of inflation and unemployment? and, therefore, What trade-offs and sacrifice ratios are implied?

\footnotetext{
${ }^{1}$ Hysteresis in Spain is related to the existence of high firing costs and long unemployment benefit duration See, e g, Bentolila and Dolado (1994), Dolado and López-Salido (1996) and Dolado and Jimeno (1997)
} 
Following King and Watson (1994) we choose three identification outlines which share the same reduced form. Yet, as mentioned earlier, they have substantialy different implications for the trade-off between unemployment and inflation, and for the interpretation of particular historical episodes. These outlines are tentatively labeled as: i) real business-cycle, ii) monetarist, and iii) keynesian, respectively. Given that the three identification outlines fit the data equally well, some information outside the model will be needed in order to choose a preferred outline among the three available possibilities.

At this stage, it is important to remark that we introduce several modifications to the King and Watson (1994)' methodology. First, we add some exogenous variables supposedly capturing some further supply shocks stemming from the "small open" economy nature of Spain. Secondly, we modify their "keynesian" and "monetarist" identification strategies by choosing outlines in which the shortrun impact of demand shocks on unemployment is maximized, under the first case, and where inflation is completely dominated by demand shocks in the long-run, under the second case. We believe that both modifications lead to neater interpretations of the underlying conceptual outlines. Thirdly, we use prior information related to the nature of the shocks in various significant historical episodes during the sample period to select a single identification outline out of the three available ones. And finally, we check the robustness of the results in the bivariate SVAR by adding a third variable to the VAR which enables to separate monetary from fiscal shocks within the demand class of shocks.

The rest of the paper is structured as follows. We begin in Sect. 2 by discussing the identification issues related to a bivariate VAR of inflation and unemployment and the possible identification outlines considered in the paper. In Sect. 3, we discuss the properties of the data and report the empirical results. In Sect. 4, we consider the stability of our estimates across different subperiods and the plausibility of the different outlines in explaining various significant disinflationary episodes in the recent history of Spain. In Sect.5, we address the robustness of some key parameter estimates to changes in the identifying restrictions. Finally, in Sect.6, some conclusions are drawn.

\section{Economic and econometric issues}

\subsection{Structural VAR representation and the identification problem}

Let us assume that the Phillips curve takes the following structural representation:

$$
\Delta u_{t}=\lambda \Delta \pi_{t}+\sum_{j=1}^{p} \alpha_{u \pi, j} \Delta \pi_{t-j}+\sum_{j=1}^{p} \alpha_{u u, j} \Delta u_{t-j}+\varepsilon_{t}^{s}
$$

where $\lambda$ indicates the contemporaneous effect of changes in the inflation rate $(\Delta \pi)$ on the unemployment rate changes $(\Delta A)$, and $\varepsilon_{t}^{s}$ is an i.i.d. structural shock with zero mean and variance $\sigma_{1}^{2}$, which will be defined below. 
This expression is not the usual one found in the empirical analysis of the Phillips curve. The differences can be stated as follows. First, unemployment appears in the LHS on (1) rather than in the RHS and the opposite happens with inflation; the reason is that, following King and Watson (1994), we define the Phillips trade-off as the ratio of the change in unemployment rate to the change in inflation rate, i.e. $(\partial u / \partial \pi)$. This is the inverse of the traditional measure $(\partial \pi / \partial u$, see, e.g. Gordon, 1990, and the references therein), and will be useful in the previous form because the hypothesis of absence of trade-off corresponds to a zero value for the former expression, instead of $-\infty$ as the latter one. Secondly, we express the relationship in first differences, rather than in levels, accounting for the importance of both hysteresis mechanisms in the unemployment rate and high persistence in the inflation rate. Both stochastic properties are well documented elsewhere and can be taken as "stylized facts" of the Spanish economy over the sample period used in this paper'.

In order to close the model, we next consider the demand side of the economy, represented through the following equation:

$$
\Delta \pi_{t}=\delta \Delta u_{t}+\sum_{j=1}^{p} \alpha_{\pi \pi, j} \Delta \pi_{t-j}+\sum_{j=1}^{p} \alpha_{\pi u, j} \Delta u_{t-j}+\varepsilon_{t}^{d}
$$

where the parameter $\delta$ reflects the contemporaneous effect of changes in unemployment on the inflation changes, and $\varepsilon_{t}^{d}$ is another i.i.d. structural shock with zero mean and variance $\sigma_{2}^{2}$ which again is yet to be defined.

Whether the system (1)-(2) is an adequate representation of the supply and demand sides of the economy is a debatable issue. To shed some light on our chosen interpretation, we first summarize the key points somehow heuristically; and, next, we will proceed to formalize those ideas, rearranging (1) and (2) in a more familiar SVAR context.

Let us start by interpreting Eq. (1). It can be obtained from standard pricesetting and a wage-setting equations given by

$$
\begin{aligned}
P & =A^{-1}(1+\mu) W \\
W & =P^{e} A F\left(u, u_{-1}, z\right)
\end{aligned}
$$

where $P=$ price level, $W=$ nominal wage, $P^{e}=$ expected price level; $\mu=$ price-cost mark-up, $\mathrm{z}=$ wage pressure (aggregate supply) variables, $A=$ productivity. Equation (3) corresponds to non-competitive price setting under a constantreturn-to- scale production function and (4) is the typical wage-setting relation underlying many theories of wage determination, where the presence of $u_{-1}$ allows for hysteretic mechanisms ${ }^{3}$. Substituting (4) in to (3), and log-linearizing yields

$$
\pi=\pi^{e}+\mu+z-\xi_{1} u+\xi_{2} u_{-1}
$$

\footnotetext{
${ }^{2}$ See, for instance, Dolado and López-Salido (1996) and Andrés (1991) where a battery of unit root tests cannot reject the null hypothesis of a unit root in both series

${ }^{3}$ See, e g, Layard et al (1991) for a good review of hysteresis models
} 
Next, we assume that $\pi_{t}^{e}=\pi_{t-1}$, as in the NAIRU literature; that there is full hysteresis, so that $\xi_{1} u-\xi_{2} u_{-1}$ is proportional to $\Delta u$; that the markup $\mu$ is constant; and that $z$ is a process governed by the innovation $\varepsilon^{s}$. Then, inverting Eq. (5) with $u$ as the dependent variable yields an equation similar to (1).

As regards Eq. (2), the easiest way to interpret it is as an aggregate demand equation where output growth $(\Delta y)$ is just a function of the acceleration of real money balances ${ }^{4}$. Using Okun's law to convert $\Delta y$ into $\Delta u$, and assuming that the innovation to $\Delta^{2} m$ is $\varepsilon^{d}$, yields an equation that, when inverted, looks like (2).

As is a standard practice in the literature on SVAR (see Blanchard and Quah, 1989), it is assumed that $\varepsilon^{d}$ and $\varepsilon^{s}$ are orthogonal processes. Thus, the system formed by (1) and (2) is not identified unless one further restriction is imposed. To deal more formally with the identification problem, we use the stacked SVAR form ${ }^{5}$ :

$$
\begin{gathered}
\alpha(L) X_{t}=\mu+\varepsilon_{t} \\
\alpha(L)=\sum_{j=0}^{p} \alpha_{j} L^{J} \quad ; \quad X_{t}=\left(\Delta u_{t}, \Delta \pi_{t}\right)^{\prime} ; \\
\varepsilon_{t}=\left(\varepsilon_{t}^{\delta}, \varepsilon_{t}^{d}\right)^{\prime} \quad ; \quad E\left(\varepsilon_{t} \varepsilon_{t}^{\prime}\right)=\sum=\left[\sigma_{i j}\right] \quad i, j=1,2 ;
\end{gathered}
$$

where $\mu$ is a vector of deterministic terms, and:

$$
\alpha_{0}=\left(\begin{array}{cc}
1 & -\lambda \\
-\delta & 1
\end{array}\right) \quad ; \quad \alpha_{j}=\left(\begin{array}{ll}
\alpha_{u u_{j}} & \alpha_{u \pi_{j}} \\
\alpha_{\pi u_{j}} & \alpha_{\pi \pi_{j}}
\end{array}\right) j=1, \ldots, p
$$

As noted earlier, we interpret Eq. (1) as the Phillips curve. Correspondingly, the structural disturbance $\varepsilon_{t}^{s}$ in expression (1) corresponds to a supply shock. Conversely, the structural error term $\varepsilon_{t}^{d}$ in (2) is interpreted as a demand shock. We will assume that shocks are mutually uncorrelated, $\sigma_{12}=0$, so that any contemporaneous correlation between $\pi_{t}$ and $u_{t}$ arises from nonzero values of the parameters $\lambda$ and $\delta$. This simple analytical framework will allow us to address a number of relevant issues:

(i) the estimation of the short- and long-run effects of both demand and supply shocks on unemployment and inflation, since the specification in first differences implies that the shocks have potentially long-lasting effects.

(ii) the estimation of the Phillips curve trade-off (PTO, henceforth), namely, the inverse of the slope of the Phillips Curve. This concept traces out the relative dynamic effects of demand shocks on unemployment and inflation. Formally, it can be computed as the following long-term derivative:

$$
P T O_{k}=\frac{\partial u_{t+k} / \partial \varepsilon_{t}^{d}}{\partial \pi_{t+k} / \partial \varepsilon_{t}^{d}} \quad ; \quad k=0,1, \ldots, \infty
$$

\footnotetext{
${ }^{4}$ The possibility of extending this set of arguments is discussed in Sect 5

${ }^{5}$ Notice that we write down the model in first differences, so that both $u_{t}$ and $\pi_{t}$ are assumed to 1(1) and not cointegrated See Sect 3 for further details
} 
(iii) tests for both long and short-run neutrality; i.e., the verticality of the short and long-run Phillips curve. These hypotheses hold when expression 7 is zero for $k=0$ and $k \rightarrow \infty$, respectively.

From the previous discussion, it is clear that the structural model given by the SVAR System in (6) is not identified. To see this consider the equivalent reduced form VAR derived from the $\operatorname{model}^{6}$ :

$$
\begin{aligned}
& \Delta u_{t}=a(L) \Delta u_{t-1}+b(L) \Delta \pi_{t-1}+e_{u t} \\
& \Delta \pi_{t}=c(L) \Delta u_{t-1}+d(L) \Delta \pi_{t-1}+e_{\pi t}
\end{aligned}
$$

which in stacked form can be written as:

$$
\Gamma(L) X_{t}=e_{t}
$$

where $e_{t}=\left(e_{u t} e_{\pi t}\right)^{\prime}$ is a vector of zero-mean identically distributed innovations; $\Gamma(L)=I-\Gamma_{1} L-\Gamma_{2} L^{2}-\ldots-\Gamma_{p} L^{p}$ is an autorregressive polynomial lag matrix with all its roots outside the unit circle; and, $E\left(e_{t}, e_{t}^{\prime}\right)=\Omega=\left[\omega_{i j}\right]$ is the variancecovariance matrix of the reduced form residuals.

Comparing (6) and (9), the following relationships hold: $\Gamma_{i}=-\alpha_{0}^{-1} \alpha_{i}$, and $e_{t}=\alpha_{0}^{-1} \varepsilon_{t}$. Thus, the matrices $\alpha_{i}$ and the variance covariance matrix of the structural shocks, $\Sigma$, are determined by the following set of equations:

$$
\begin{aligned}
-\alpha_{0}^{-1} \alpha_{i} & =\Gamma_{i} \quad, \quad i=1, \ldots, p \\
\alpha_{0}^{-1} \sum\left(\alpha_{0}^{-1}\right)^{\prime} & =\Omega
\end{aligned}
$$

The identification problem can be stated as follows. The first set of equations linking the variance of $e_{t}$ and $\varepsilon_{t}$ imposes no restrictions on $\alpha_{0}$. That is, there are no restrictions on the coefficients on lags entering the dynamic system (6). Thus, Eq. (11) determines the unknowns in both $\alpha_{0}$ and $\Sigma$ as a function of the variance-covariance matrix of the reduced form innovations. Yet, since $\Omega$ is a $2 \times 2$ symmetric matrix, only three unknown parameters can be identified in $\alpha_{0}$ and $\Sigma$. Hence, even after assuming that $\sigma_{12}=0$, the four parameters $\sigma_{11}, \sigma_{22}, \lambda$ and $\delta$ cannot be separately identified, and one additional restriction is required.

Nevertheless, by adding whatever single restriction one should wish, all the resulting models are just-identified and, hence, their unrestricted reduced forms fit the data equally well. Notwithstanding, each one will have different implications for disentangling: i) the sources of business cycle fluctuations and stochastic trends; ii) the trade-off between unemployment and inflation; and, iii) the policy interpretations of particular historical episodes. In this respect, the following section explores three alternative identifying restrictions which seem to us especially meaningful from an economic point of view. The three schemes share the orthogonality assumption, $\sigma_{12}=0$, and none of them imposes long-run verticality of the Phillips curve, since this is one of the propositions we wish to test.

\footnotetext{
${ }^{6}$ Notice that, for the sake of simplicity, deterministic terms have been omitted from the equations
} 


\subsection{Three alternative identification schemes}

A simple comparison of expressions (6) and (9) implies that the innovations of the reduced form, $e_{u t}$ and $e_{\pi t}$, can be expressed as linear combinations of the structural shocks. In particular, simple derivations lead to: $e_{u t}=D\left(\lambda \varepsilon_{t}^{d}+\varepsilon_{t}^{s}\right)$ and $e_{\pi t}=D\left(\varepsilon_{t}^{d}+\delta \varepsilon_{t}^{s}\right)$, with $D=(1-\lambda \delta)^{-1}$.

Using these relationships and the VAR reduced form (expressions (8a) and (8b)) a closed-form solution for the long-run PT0 (expression (7)) can be calculated $^{7}$ :

$$
\lim _{k \rightarrow \infty} P T 0_{k}=\frac{(1-d(1)) \lambda+b(1)}{(1-a(1))+\lambda c(1)}
$$

Thus, the long-run $\mathrm{PTO}_{k}$ is a function of the short-run $\mathrm{PTO}_{k}(\lambda)$ and the long-run relationships (gains) between unemployment and inflation (the lagpolynomials of the reduced form VAR evaluated at $\mathrm{L}=1$ ). Notice also that if $c(1)<0$, the long-run $\mathrm{PTO}_{k}$ does not have any discontinuity for $\lambda<0$, since the denominator in expression (12) will always be positive, assuming that $0<a(1)<1$.

As noted above, to just-identify the model we can use both the short-run and long-run restrictions implied by alternative economic models. In particular, in this section we discuss three different sets of identifying restrictions based upon: (i) a real business cycle approach, (ii) a rational expectations-monetarist approach, and (iii) a keynesian approach, respectively.

\subsubsection{A real business cycle approach $(\mathrm{RBC})$}

From this theoretical standpoint, real variables, such as the unemployment rate, are assumed not to be affected by nominal shocks in the short-run. That is $e_{u t}=\varepsilon_{t}^{s}$ and, hence, identification is achieved by setting $\lambda=0$, i.e. the short-run tradeoff is zero. This restiction has been recently used by King and Watson (1994) as an interpretation of the RBC characteristics. Notice that it does not imply that the long-run Phillips trade-off is necessarily zero since, as can be seen from expression (12) that result will only hold if $b(1)=0$. Hence, the existente of longrun Granger-causality from inflation to unemployment in the VAR is crucial for the existence of a long-run $\mathrm{PTO}_{k}$, in this case.

\subsubsection{A monetarist approach (M)}

From this viewpoint, we follow the monetarist dictum "inflation is always a monetary phenomenon in the long-run". We broadly interpret this dictum as saying that supply shocks do not affect the long-run level of inflation, i.e.

\footnotetext{
7 To obtain that expression we solve out (8a) and (8b) for the long-run trends in unemployment and inflation
} 
$\left(\partial u_{t+k} / \partial \varepsilon_{t}^{s}\right)=0$ as $k$ tends to infinity ${ }^{8}$. It is easy to check that this restriction implies $\delta=-c(1) / l-a(1)$, which, together with $\lambda=\left(\omega_{12}-\delta \omega_{11}\right) /\left(\omega_{22}-\delta \omega_{12}\right)$ obtained from (11), defines a corresponding value for $\lambda$.

This identification assumption is similar in spirit to that used in Roberts (1993) in identifying "core inflation" in the US. King and Watson (1994), in turn, use a so-called Rational Expectations-Monetarist identification whereby an implicit value of $\lambda$ is estimated as $\operatorname{cov}(u, m) / \operatorname{cov}(p, m)$ where $m$ stands for unanticipated money (see Barro and Rush 1980). However, since the validity of the hypothesis that only unanticipated money matters in dubious for the Spanish economy (see Dolado 1984) we rather prefer the identification restriction chosen here. Notice that, in this case, the PTO will only be zero if $\lambda=b(1) / 1-d(1)$.

\subsubsection{A keynesian approach $(\mathrm{K})$}

The keynesian view is interpreted here as implying that the effect of demand shocks on short-run (one-quarter) unemployment fluctuations is maximised, whereas in the long-run both types of shock are allowed to affect unemployment in a possibly permanent way. This possibility arises by choosing a value of $\lambda$ such that it maximises the ratio $\lambda / 1-\lambda \delta$ (see the relation between $e_{u}$ and $\left.\varepsilon^{d}\right)$ subject to the restriction, $\delta=\left(\omega_{12}-\lambda \omega_{22}\right) /\left(\omega_{11}-\lambda \omega_{12}\right)$. This procedure differs from the one chosen by King and Watson (1994) who implicitly define $\lambda$ by using the contemporaneous value of $u_{t}$ as an instrument to estimate (1) or equivalently, estimating (1) by OLS using the reverse regression of $\pi_{t}$ onto $u_{t}$ and relevant lags, as performed by Gordon (1970) and other researchers in the Keynesian tradition. Again, we believe that our identification outline is neater.

\subsection{The Lucas-Sargent critique}

In this section we just want to point out briefly that the fact that we cannot reject a unit root in the inflation process over the sample period saves the analysis from the traditional Lucas-Sargent criticism. The critique runs as follows. Suppose that unemployment is simply a function of unexpected inflation as in Lucas (1972a,b) and that this hypothesis is tested in the following expectations-augmented version of $(8 \mathrm{a})$

$$
u_{t}=\lambda \pi_{t}-\lambda^{*} \pi_{t}^{e}+\eta_{t}
$$

where $\pi_{t}^{e}=E_{t-1}\left(\pi_{t}\right)$, and the natural rate hypothesis implies that $\lambda=\lambda^{*}$.

\footnotetext{
${ }^{8}$ It could well be possible that a supply shock might lead to a permanent change in the growth of money and thus on inflation in the long-run if monetary policy endogenously responds to that type of shock However, in order to preserve the interpretation of the demand shock as a monetary one, orthogonal to the supply shock, in the bivariate model we exclude this possibility from the outset Thus, if such an endogenous component of monetary policy exists, the results below should be interpreted with a dose of caution
} 
Assume that $\pi_{t}$ is governed by the process $\pi_{t}=\rho_{1}(L) \pi_{t-1}+\rho_{2}(L) u_{t-1}+\varepsilon_{t}$, where, without affecting the basic result, the contemporaneous value of $u_{t}$ has been excluded. Then, under rational expectations, $\pi_{t}^{e}=\rho_{1}(L) \pi_{t-1}+\rho_{2}(L) u_{t-1}$. Thus, the reduced for unemployment and inflation relation is given by

$$
u_{t}=\lambda \pi_{t}-\lambda^{*}\left[\rho_{1}(L) \pi_{t-1}+\rho_{2}(L) u_{t-1}\right]+\eta_{t}
$$

so that the long-run trade-off is $\partial u / \partial \pi=\left(\lambda-\lambda^{*} \rho_{1}(1)\right) /\left(1+\lambda^{*} \rho_{2}(1)\right)$. Hence, even if there is long-run neutrality $\left(\lambda=\lambda^{*}\right)$ estimation of (14) would lead to an apparent long-run trade-off unless $\rho_{1}(1)=1$. Naturally, the existence of a unit root in $\pi_{t}$ implies precisely that the condition $\rho_{1}(1)=1$ holds and, therefore, the criticism does not apply in our case.

\section{Empirical results}

\subsection{The data set and reduced-form estimates}

The data set spans the period 1964:1-1997:4 and consists of: the Spanish CPI annual inflation rate $\left(\pi_{t}=\Delta_{4} \ln p_{t}\right)$, the Spanish unemployment rate $\left(u_{t}\right)$ the EU(15) (excluding Spain) CPI annual inflation rate $\left(\pi_{t}^{*}=\Delta_{4} \ln p_{t}^{*}\right)$ and the $\mathrm{EU}(15)$ unemployment rate $\left(u_{t}^{*}\right)^{9}$. All data are quarterly, seasonally unadjusted and are drawn from the Statistical Bulletin of the Banco de España and OECD Economic Outlook (various issues).

As can be seen in Fig. 1, both Spanish inflation and unemployment rates moved together up to the late 1970 s, reflecting the stagflationary period that followed the oil price crises. Later, their correlation becomes negative, with the exception of the 1986-1991 subperiod where seemingly no correlation is present and the last two years in the sample where a "virtuous process" seems to be taking place. Nevertheless, as these simple movements are dominated by both domestic and foreign demand and supply shocks, they are not informative about their driving forces. To disentangle the source of those correlations and to analyze the PTOs following a demand shock is the task of the rest of the paper.

Table 1 shows a summary of results from the estimation of the VAR with lag length ranging from 4 to 8 quarters. The VAR in $\left(\Delta u_{t}, \Delta \pi_{t}\right)^{\prime}$, given by Eqs. (8a) and $(8 \mathrm{~b})$, was augmented with a constant term, three seasonal dummies, current and lagged values of $\Delta u_{t}^{*}$ and lagged values of $\Delta \pi_{t}^{*}$, accounting for external shocks leading to shifts in the aggregate demand relations and the Phillips curve. Both $\Delta u_{t}^{*}$ and $\Delta \pi_{t}^{*}$ are treated as exogenous, given the small-open economy assumption supported by the fact that the Spanish variables do not Grangercause EU(15) variables. In this respect, two comments are in order. First, the current value $\Delta \pi_{t}^{*}$ has been excluded since it turns out to be non-significant and because including it seems to run directly against the spirit of the RBC

\footnotetext{
${ }^{9}$ We choose the transformation $\Delta_{4} \ln p_{t}$ rather than $4 \Delta \ln p_{t}$ since there is strong evidence that the stationarity tranformation of the (log of) price level in Spain (and in the EU) is $\Delta \Delta_{4} \ln p_{t}$ See Espasa and Cancelo (1993)
} 


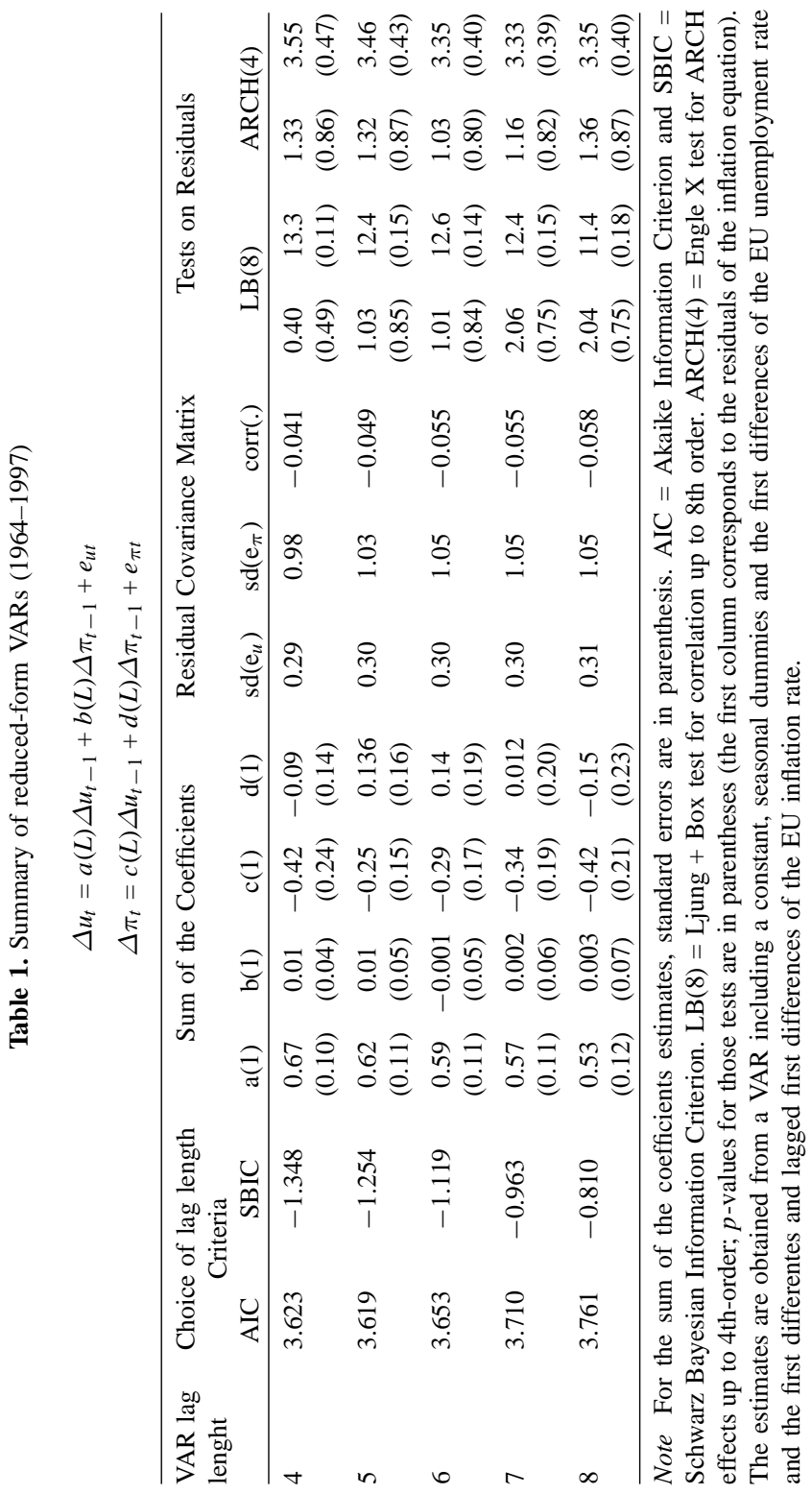


identification strategy whereby no demand shocks, either domestic or foreign, should affect unemployment in the short-run. Secondly, reparameterizing the long-run solution of the VAR in terms of inflation and unemployment differentials cannot be rejected at standard confidence levels. Thus, in this sense the structural shocks $\varepsilon_{t}^{d}$ and $\varepsilon_{t}^{s}$ can be loosely interpreted as idiosyncratic national supply and demand shocks though, for the sake of brevity, we will stick to the labels in Sect.2. And third, the foreign variables have also been introduced to help explaining a possible structural break in the late seventies. In this respect, we also introduced some oil-price series and some (foreign) labour-market variables (such as replacement ratios) directly, but they did not prove to be significant once the foreign variables are included.

It should also be noticed that there are no signs of cointegration among any of the series and, thus, that the specification of the VAR in first-differences seems appropriate ${ }^{10}$. Furthermore, according to various portmanteau test on serial correlation and tests on ARCH in the error terms, reported in Table 1, there is no sign of misspecification in the VAR. As for the choice of the VAR lag length, both AIC and SBIC criteria point out to 5 and 4 lags, respectively. Nevertheless, results for lag length ranging from 4 to 8 are also reported in Table 1 to highlight their robustness for such a choice.

Various implications follow from the above results. First, the correlation between the VAR innovations $\left(e_{u}\right.$ and $\left.e_{\pi}\right)$ is small, implying that $\lambda \cong-\delta \omega_{11} / \omega_{22}$. Secondly, the estimates of $b(1)$ and $d(1)$ are found to be small and non significant; that $b(1)$ is non significant implies that there is no Granger-causality from inflation to unemployment (given foreign inflation and foreign unemployment). Thirdly, the estimates of $a(1)$ and $c(1)$ are more sizeable and significant, albeit the second is marginally so; that $c(1)$ is significant and negative implies that there is Granger-causality from unemployment to inflation. And finally, since $0<a(1)<1$ and $c(1)<0$, it follows from expression (12) in Sect. 2 that the long-run PTO is a monotonic function for negative values of $\lambda$. Figure 2 depicts the estimated long-run trade-offs as a function of $\lambda$ for the various lag lengths reported in Table 1. It can be observed that, for small values of $\lambda$, the PTO is almost nil whilst, for high values, it is around -2.0. The choice of lag length, in turn, does not seem to have any noticeable effect on these estimates.

\subsection{Impulse response functions and variance decompositions}

Let us now turn to the results under the different identification schemes. We begin the discussion with the keynesian (K) identifying restrictions. Using the procedure described in Sect. 2.2.3, $\lambda=-0.25$ proved to maximise the short-run demand effects on unemployment under $\mathrm{K}$ while the corresponding values of $\delta$ is 2.8. Figure 3a depicts the impulse-response (IR) functions of unemployment and

\footnotetext{
${ }^{10}$ Conditioning on $\Delta u_{t}^{*}$, and $\Delta \pi_{t-1}^{*}$, Johansen's maximum eigenvalue test for cointegration between $u_{t}$ and $\pi_{t}$ yields 933 (for $r=0$ ) and 536 (for $r=1$ ) where $r$ is the cointegration rank The critical values are 1490 and 818 , respectively
} 


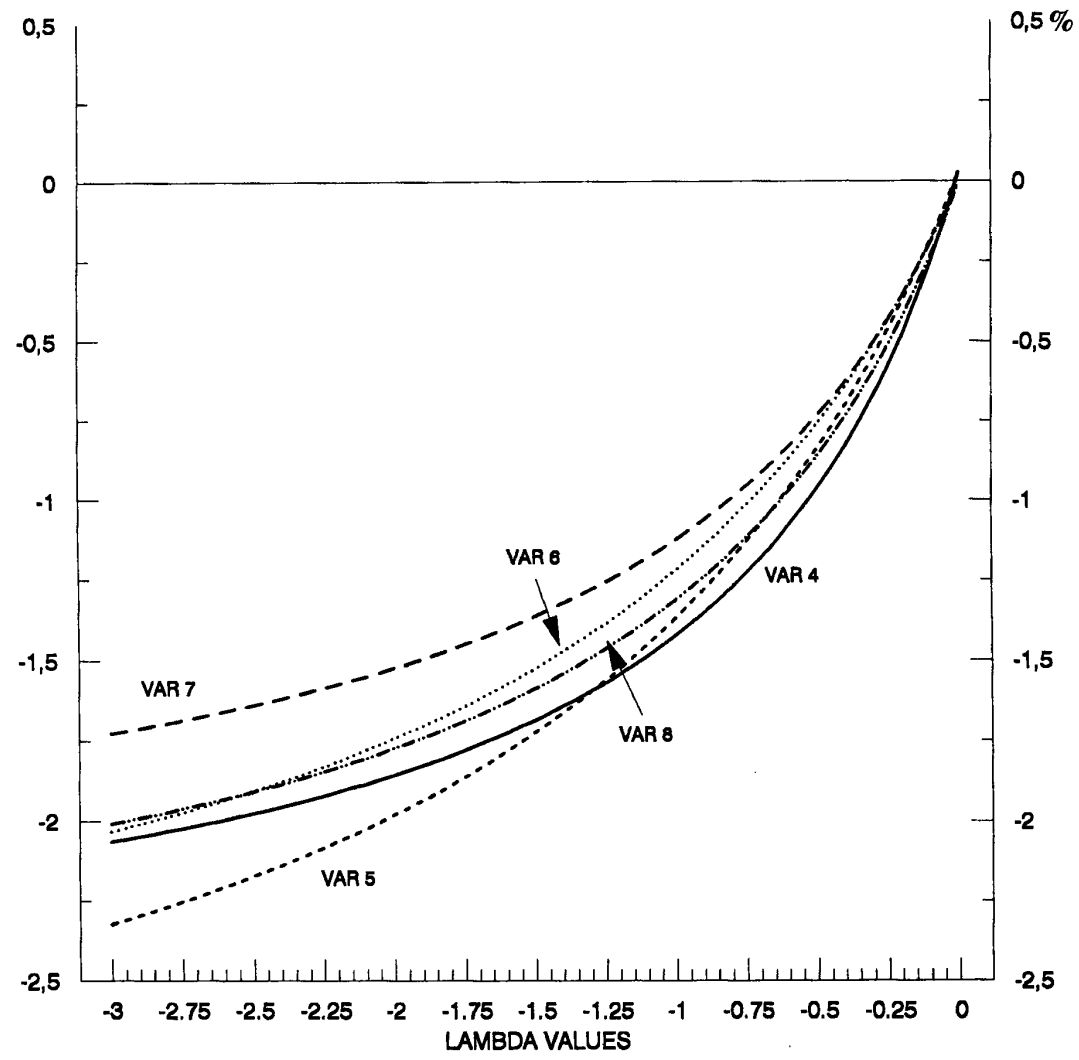

Fig. 2. Implied long-run Phillips trade-offs

inflation to a unit demand shock whereas the bottom panel depicts the Phillips trade-off for various horizons; the short-run trade-off is -0.3 whilst the long-run trade-off, which is achieved after four years, is -0.6 .

As regards the $M$ identifying restriction, $\lambda=-0.12$ turned out to be the value obtained from the procedure described in Sect. 2.2.2, yielding $\delta=1.21$. Figure $3 \mathrm{~b}$ shows the same information as above. Since inflation is a monetary phenomenon in the long-run under this scheme, its IR function converges quickly towards unity, whereas unemployment falls by 0.3 percentage points in the long-run. The PTO is -0.12 in the short run and, after two years, reaches a steady state value of -0.3 . Both trade-offs are smaller (in absolute value) than under the $K$ scheme, but they turn out to be statistically different from zero.

Next, we turn to the RBC scheme where $\lambda=0$ and so $\delta=-0.14$. Since $b(1)=d(1) \cong 0$, the RBC implies a vertical long-run Phillips curve. Figure $3 \mathrm{c}$ shows a similar IR function for inflation to the one obtained under the M scheme. Naturally, what differs is the shape of the unemployment IR function which, under the RBC assumption, implies an almost zero trade-off at all horizons. 


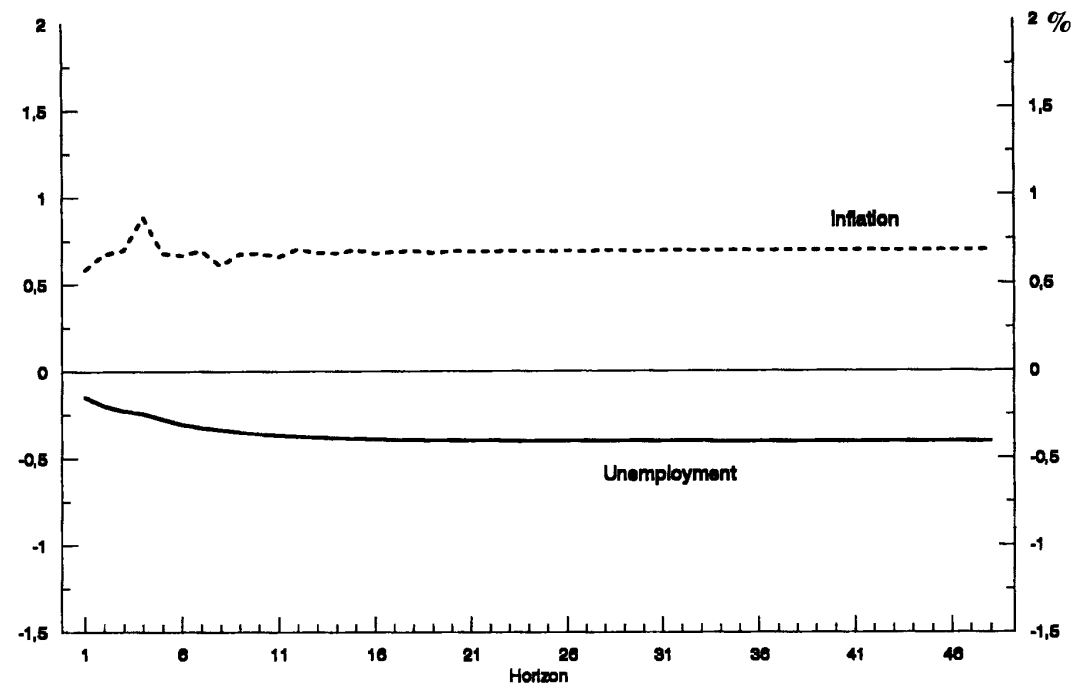

PHILIPS CURVE TRADE-OFF8

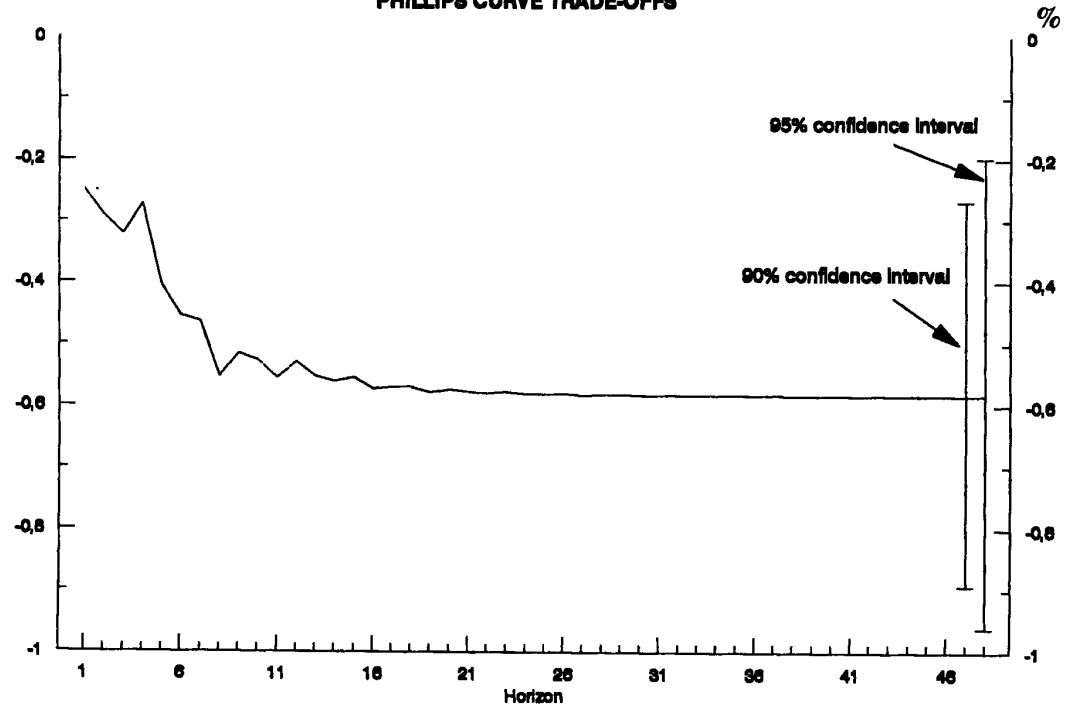

Fig. 3a. Unemployment and inflation responses in Keynesian model (Responses to a unit demand shock)

Table 2 summarises the importance of demand shocks in explaining the variability of forecast errors of inflation and unemployment at various horizons, by means of the forecast error-variance decomposition (VD) method. Under the $\mathrm{K}$ scheme, demand shocks explain $100 \%$ of unemployment variability, reflecting that inflation does not Granger-cause unemployment, and only $12 \%$ of inflation 


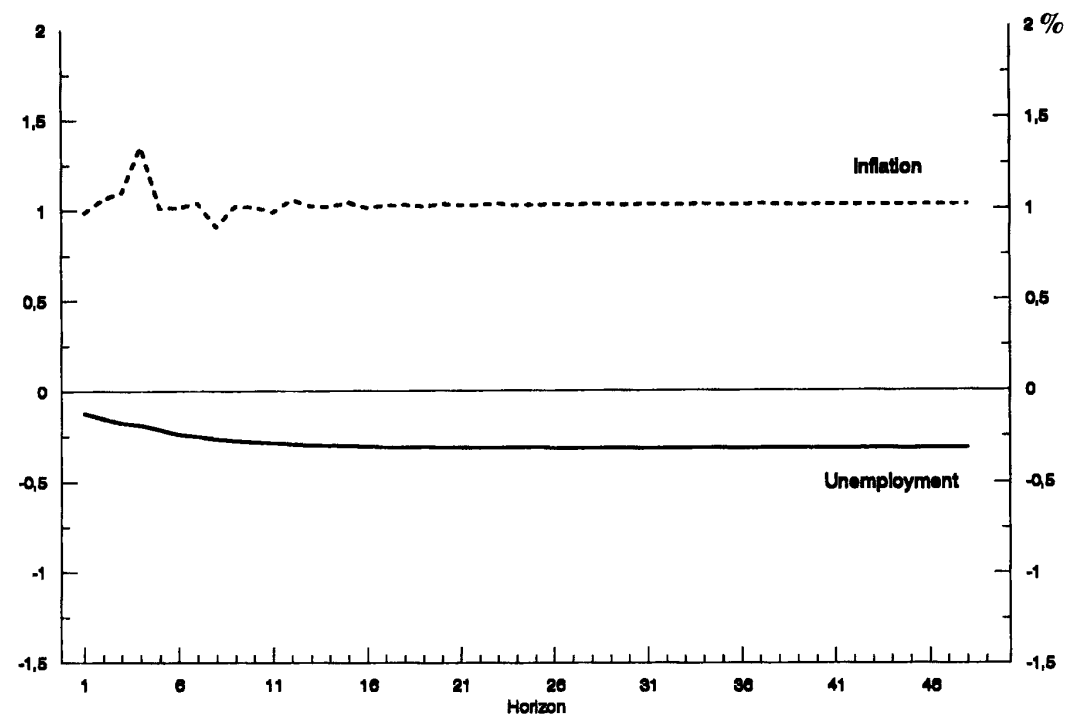

PHIUPS CURVE TRADE-OFFs

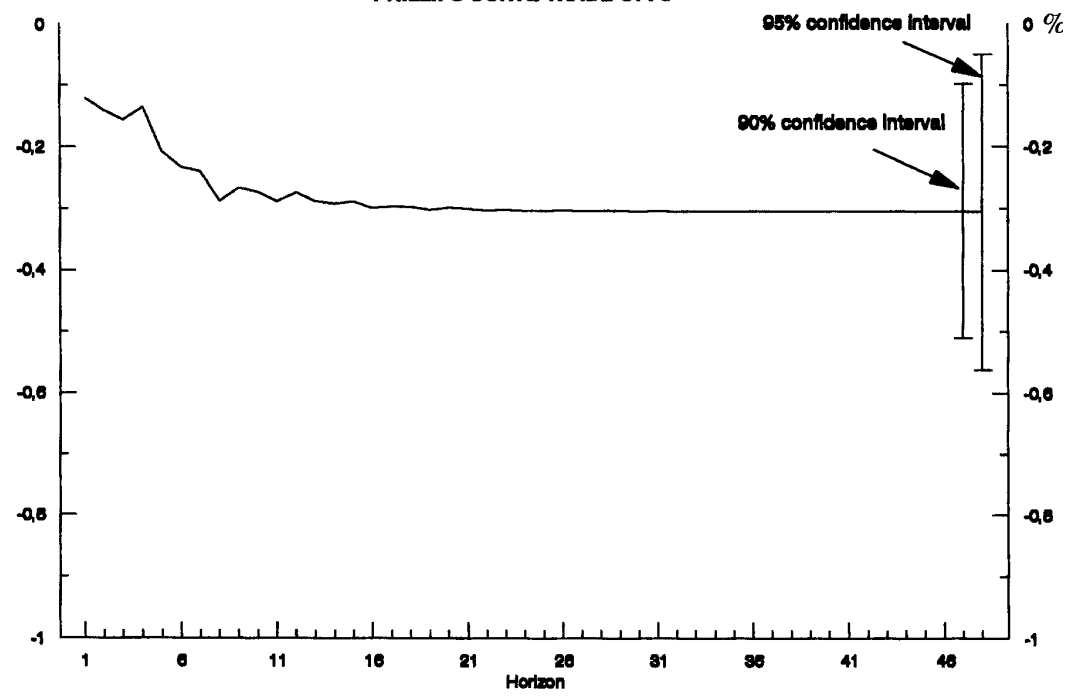

Fig. 3b. Monetarist model (responses to a unit demand shock)

variability (the remaining proportions are explained by supply shocks). As expected, under the $M$ scheme, $\varepsilon_{t}^{d}$ explains $15 \%$ of the unemployment variability and almost $90 \%$ of inflation variability. Finally, under the RBC scheme, unemployment variability is completely explained by $\varepsilon_{t}^{s}$, whereas $93 \%$ of inflation variability is explained in the short-run and almost $60 \%$ in the long-run by those shocks. 


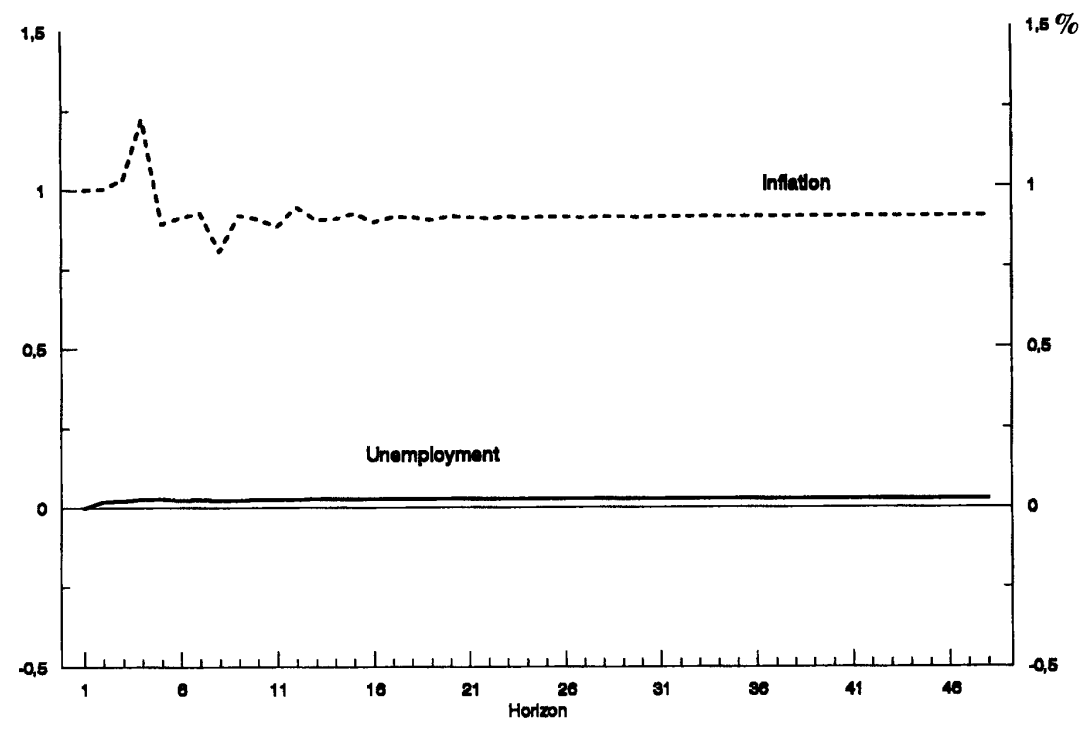

PHILIPS CURVE TRADE-OFFs

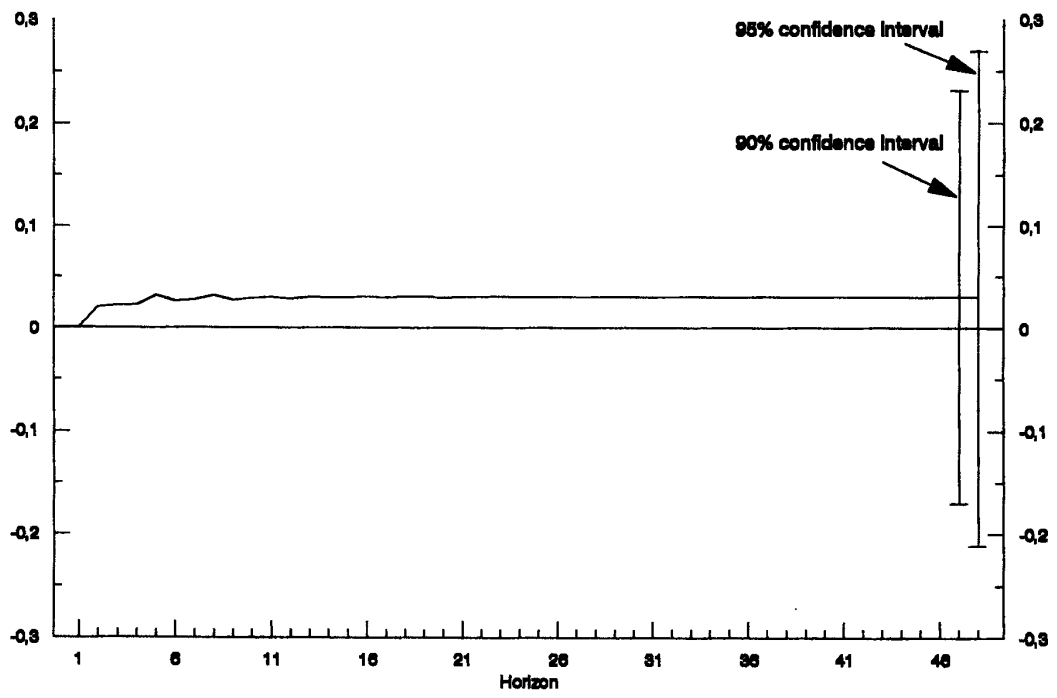

Fig. 3c. RBC model (responses to a unit demand shock)

\subsection{Sacrifice ratios}

Once we have examined the different trade-offs implied by the various identification outlines, we turn to an alternative measure of the cost of disinflation. Table 3 shows the estimated dynamic responses of the levels of unemployment 
Table 2. The role of demand shocks in variance decompositions (1964-1997)

\begin{tabular}{lcccccc}
\hline Horizon & \multicolumn{2}{c}{$(\lambda=-0,25)$} & \multicolumn{2}{c}{$(\lambda=-0,12)$} & \multicolumn{2}{c}{$(\lambda=0)$} \\
& \multicolumn{2}{c}{ Keynesian model } & \multicolumn{2}{c}{ Monetarist model } & \multicolumn{2}{c}{ RBC model } \\
& $u$ & $\pi$ & $u$ & $\pi$ & $u$ & $\pi$ \\
\hline 1 & 100.00 & 11.00 & 15.32 & 89.98 & 0.000 & 93.03 \\
4 & 99.7 & 11.78 & 13.69 & 87.93 & 0.004 & 5759 \\
8 & 98.9 & 12.13 & 13.93 & 88.36 & 0.003 & 57.75 \\
12 & 98.8 & 12.17 & 13.94 & 88.50 & 0.003 & 57.66 \\
16 & 98.8 & 12.17 & 13.94 & 88.53 & 0.004 & 57.65 \\
$\infty$ & 98.8 & 12.17 & 13.94 & 88.53 & 0.003 & 57.64 \\
\hline
\end{tabular}

Table 3. Sacrifice ratios (SR) for A 1 percentage point permanent reduction in inflation rate (Full Sample: 1964-1997)

\begin{tabular}{lccc}
\hline Horizon & \multicolumn{3}{c}{ Keynesian model } \\
& $u$ & $\pi$ & SR \\
\hline 1 & 0.22 & -0.85 & 0.22 \\
4 & 0.35 & -1.35 & 0.35 \\
8 & 0.49 & -0.90 & 0.84 \\
12 & 0.54 & -1.03 & 1.38 \\
16 & 0.57 & -1.01 & 1.95 \\
$\infty$ & 0.59 & -1.00 & 2.54 \\
\hline \multirow{3}{*}{ Horizon } & \multicolumn{3}{c}{ Monetarist model } \\
& $u$ & $\pi$ & SR \\
\hline 1 & 0.11 & -0.96 & 0.11 \\
4 & 0.18 & -1.31 & 0.18 \\
8 & 0.25 & -0.88 & 0.43 \\
12 & 0.28 & -1.03 & 0.71 \\
16 & 0.29 & -0.98 & 1.00 \\
$\infty$ & 0.30 & -1.00 & 1.30 \\
\hline Horizon & \multicolumn{3}{c}{ RBC model } \\
& $u$ & $\pi$ & SR \\
\hline 1 & -0.22 & -1.10 & -0.02 \\
4 & -0.03 & -0.98 & -0.03 \\
8 & -0.03 & -1.01 & -0.06 \\
12 & -0.03 & -0.99 & -0.09 \\
16 & -0.03 & -1.00 & -0.12 \\
$\infty$ & -0.03 & -1.00 & -0.15 \\
\hline & \multicolumn{3}{c}{}
\end{tabular}

and inflation to an $\varepsilon_{t}^{d}$ shock that eventually leads to a $1 \%$ permanent reduction in inflation. In addition, the table shows the sacrifice ratio defined as the sum over a number of years of the incremental annual levels of unemployment following the demand shock; i.e, the sum over the period of the differences in the annual levels of unemployment with and without the demand shock ${ }^{11}$. Under a stable

${ }^{11}$ Formally, the sacrifice ratio is defined as: ao

$$
S R=\lim _{k \rightarrow \infty} \frac{\sum_{k=0}^{\infty} \text { PTO }_{k}}{\partial \pi_{t+k}=-1} .
$$


Okun's law, these sacrifice rates would be proportional to the cumulated loss in output over the relevant horizon.

The $\mathrm{K}$ identification suggests that the unemployment rate raises by $0.35 \%$ after one year, is $0.5 \%$ higher after two years, and around $0.6 \%$ higher after five years. By contrast, the $\mathrm{M}$ identification yields smaller unemployment responses: $0.18 \%$ after a year and $0.30 \%$ after the five years. Finally, under the RBC identification, unemployment is governed essentially by supply shocks, so that the reduction in inflation has negligible costs in terms of unemployment at all horizons.

The resulting sacrifice ratios over five years are, respectively, $2.5 \%, 1.3 \%$ or $0 \%$. Following the results obtained by Dolado and López-Salido (1996), the Okun's coefficient for the Spanish economy is around 2 over the sample 19701994. Consequently, the cumulated loss in output over the five-year horizon could be estimated to be $5 \%, 2.5 \%$ or $0 \%$, depending on the specific identification outline.

\section{Subsample stability and two disinflationary periods}

In this section we investigate the stability of the bivariate relation analyzed above. We began this paper by pinpointing that the late 1970s represented key years in the recent history of Spanish inflation. Thus, it seems natural to test whether that period is the natural breaking date in the sample. However, to take an "open-minded" approach on this issue, stability was tested with unknown break point tests, such as the sup-Wald statistic of Andrews (1993) with truncation fractions $(0.15,0.85)$. Using that test, we find 1979:1 as the breaking date in both equations, with p-values of around 0.04 in both cases. Moreover, the longrun PTO was marginally insignificant, for all the identification outlines, during the first subsample, suggesting that such a period was dominated by supply shocks.

However, when the VAR was re-estimated in the sample 1979:2-1997:4, the results were very similar to those obtained for the whole sample, as shown in Fig. 4 which compares the PTOs (across different values of $\lambda$ ) for the complete sample and the chosen subsample. As regards the VD analysis, which is skipped for the sake of brevity, the results were again similar to those shown in Table 2. Finally, with regard to the sacrifice ratios, the results were almost identical for the RBC and $\mathrm{M}$ outlines, while the one implied by the $\mathrm{K}$ identification was only half of a percentage point lower in the subsample.

So far we have discussed the three alternative identification schemes on equal grounds. After all, their reduced forms are identical. Are there any grounds to choosing a particular one on the basis of extraneous information to the model ${ }^{12}$ ? In this respect, we use prior information on three recent disinflationary periods to evaluate the identification schemes. The first one goes from 1987:1 to $1988: 1$

\footnotetext{
${ }^{12}$ Since the system is just-identified, it is not possible to test it in a formal way Thus, the only validity checking we can do is by using "common sense" and confronting the results with the observations and one's knowledge of economics (Leeper et al 1996)
} 


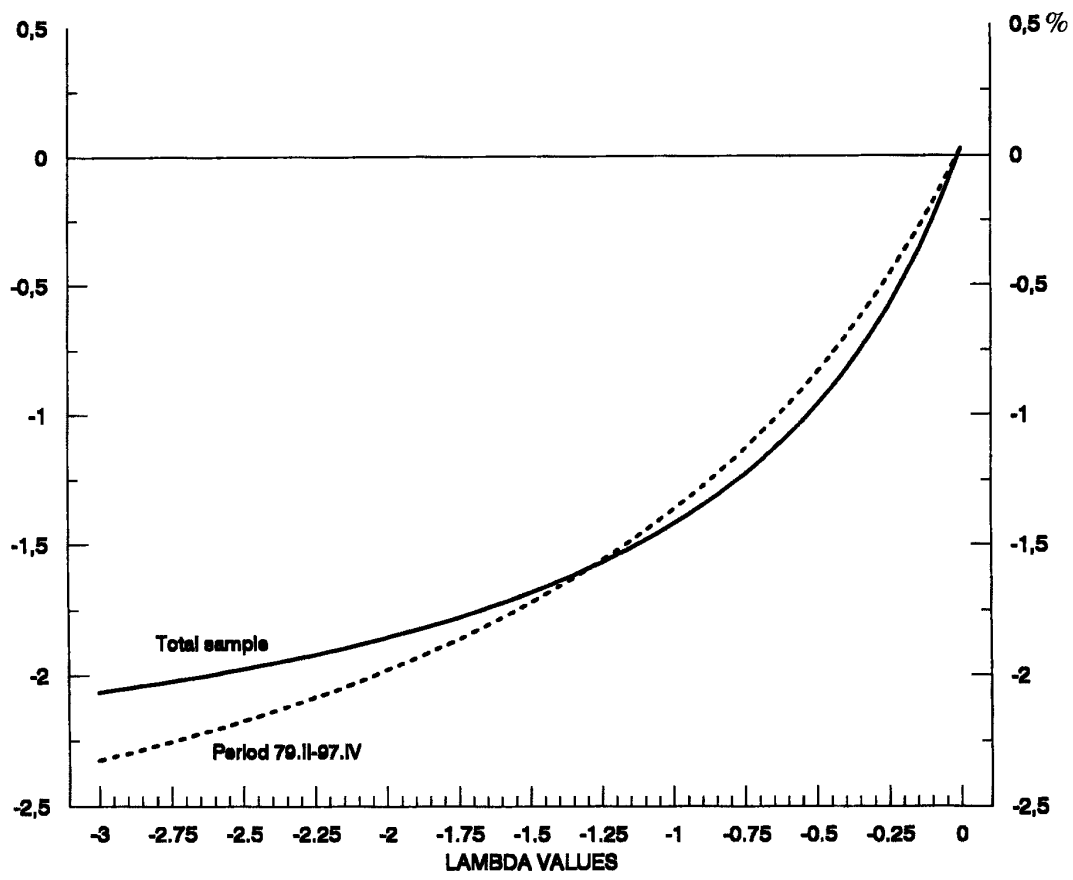

Fig. 4. Comparing long-run Phillips trade-offs (estimates from a VAR 4)

and was dominated by tighter monetary policy with interest rates raising by 5 p.p. in a single year. The second one runs from 1989:3 to 1991:3 and, while interest rates remained high and stable around $15 \%$, it was accompanied by tight credit restrictions. So, both disinflationary periods seem to follow a monetary contraction (see Escrivá and Santos 1991). Conversely, the available evidence about the third disinflationary period, which covers 1992:1 to 1993:1, points out to the effects of deregulation in labour and goods markets as the major causes behind the fall in inflation (see Dolado and Jimeno, 1997). Accordingly, we expect the first two periods to be dominated by demand shocks, whilst the last one should be explained by supply shocks.

Using the VD results for the above-mentioned episodes we found that according to the $\mathrm{M}$ scheme the contribution of demand shocks to the variance of $\Delta \pi$ during the first two subperiods was above $90 \%$, while in the third episode it was only $20 \%$. The $\mathrm{K}$ outline, in turn, explains that more than $70 \%$ of the variability is due to demand shocks in all three episodes, whereas according to the RBC scheme, it is always below 5\%. Thus, according to our prior beliefs on the distribution of shocks in each period, our hunch is that of the three cases considered above, the monetarist one is closest to the real workings of the Spanish economy. 


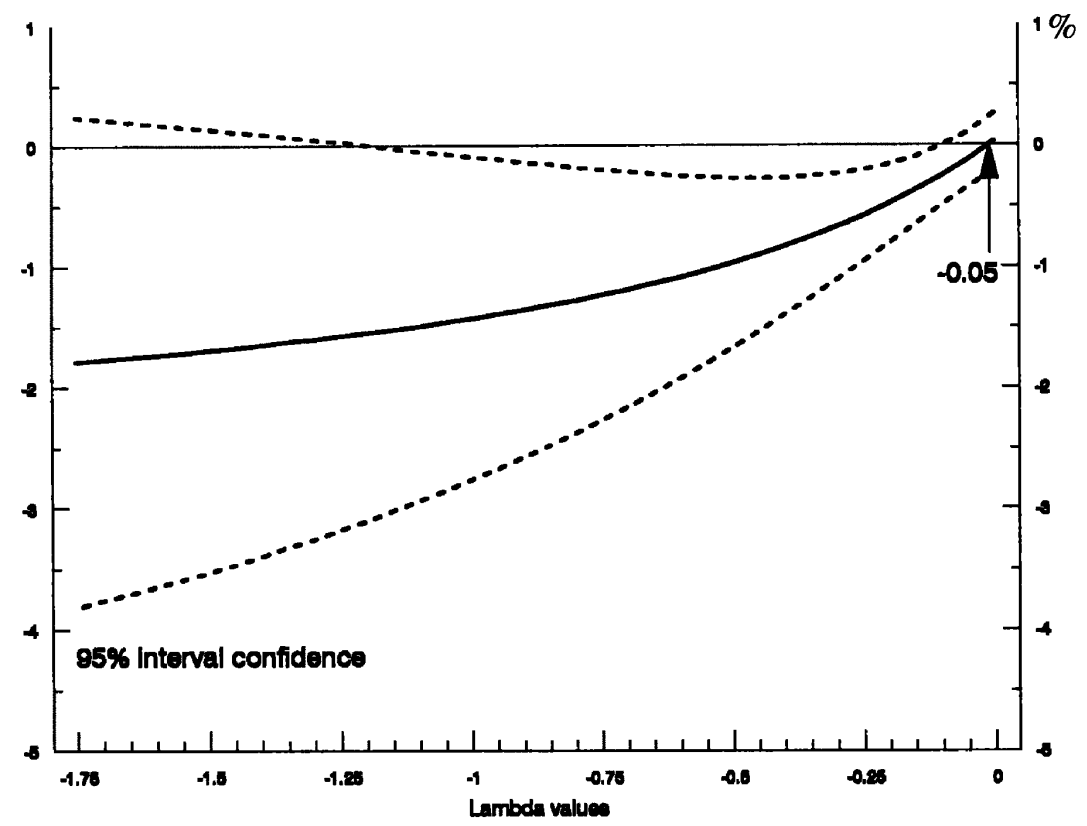

Fig. 5. Long-run Phillips trade-offs as a function of lambda (results from a VAR 4)

Finally, in order to check the robustness of our results, we report in Fig. 5, for a wide range of values for $\lambda$, the resulting point estimates and confidence intervals for the long-run PTO, showing what values of $\lambda$ are compatible with the hypothesis of a vertical long-run Phillips curve. For $\lambda<-1.27$, the estimated long-run PTO are large, though non significant. However, for $-1.27 \lambda<-0.09$, a range which includes two of the three previous outlines, the hypothesis is rejected, unless prior beliefs close to the RBC outline are assumed. Thus, the evidence points out that even under the M scheme $(\lambda=-0.12)$ the rise in unemployment/output loss, due to a disinflation led by negative demand shocks, seems to be permanent, a result which is line with the strong available evidence pointing out that the staggering rise in Spanish unemployment has a strong hysteresis component (see, e.g., Blanchard and Jimeno 1995).

\section{Robustness of the results to a trivariate VAR}

So far, we have relied upon the assumption that there are only two important shocks which can be identified from the bivariate VAR in Eqs. (1)-(2). A controversial implication of our results is that there seems to be a permanent PTO even under the sensible monetarist assumption that inflation is a purely monetary phenomenon in the long-run. Therefore, it is important to explore whether this result is robust or not to changes in the specification of the model. 
As pointed out by Evans (1994), let us suppose that there is a third shock in the system; then the identified supply and demand shocks from the bivariate VAR will be a linear combination of the three shocks. In particular, what this model identifies as a demand shock may not necessarily be a (nominal) monetary shock but a mixture of the latter and possibly a fiscal shock. After all, the underlying theory behind Eq. (2) is that of an aggregate demand equation where output depends on real money balances, government expenditure and taxes. For simplicity, the last two variables were ignored in our earlier discussion. Yet, they could be important. Hence, in our bivariate framework we are just able to identify pooled demand shocks. Thus, to disentangle a pure "monetary" shock, one possibility is to add a third variable $\left(x_{t}\right)$ to the VAR which contains direct information about the "monetary" shocks so that $\varepsilon_{t}^{d}$ can be interpreted appropriately. Empirically, this is done by adding lagged values of $x_{t}$ to the VAR in (8a)-(8b), while allowing $x_{t}$ to be influenced by contemporaneous values of $\Delta u_{t}$ and $\Delta \pi_{t}$ in its own equation (i.e., the original demand and supply shocks are treated as Wold causally prior to the third shock). The intuition behind this approach is as follows: it is assumed that an indicator of the monetary policy stance is affected both by unemployment and inflation contemporaneously, as if the monetary authorities were able to identify shocks in those variables within the current quarter, whereas the effects of the monetary innovations on the other two variables take at least one quarter to take place, in line with the traditional monetary transmission mechanism (see, for instance, Christiano et al. 1995). Thus, the innovations to $x_{t}$ are directly interpreted as "monetary" shocks.

We considered various candidates for $x_{t}$ and found the level of the intervention rate of the Bank of Spain as a suitable one ${ }^{13}$. Figure 6 depicts the IR functions of unemployment and inflation to a rise of one standard deviation in the short term interest rate. They show that the interest rate shock is rather persistent while the unemployment rises and the inflation rate falls. In Table 4 we report the corresponding sacrifice ratio, that is a cumulative permanent increase of the unemployment rate of about 0.6 p.p. per 1 p.p. of inflation reduction. Notice that, though at the margin, the hypothesis that there is a permanent PTO is not rejected at $10 \%$ significance level.

The new results arising from attempting to distinguish between monetary and non-monetary shocks yield different implications regarding the size of the sacrifice ratio, which is now halved and they yield an interesting benchmark when comparing the costs and benefits of achieving price stability, the latter being defined as an inflation rate of about 1.5 p.p., once the inflation measurement bias is taken into account. In particular, as claimed by Feldstein (1999), if the benefits of lower inflation, measured in terms of GDP gains, are permanent, via lower distortions stemming from the interaction of inflation and taxes, then, discounting an annual benefit of $\mathrm{x}$ percent of GDP at a discount rate of $\rho$ in an economy that has a normal growth rate of $2.5 \%$ a year (the Spanish normal rate over the

\footnotetext{
${ }^{13}$ Other alternative variables such as the first-differenced growth rates of M2, M3 and ALP2 or the first-differenced short-term interest rates (in particular, the interbank one-month rate), were used with less clear results
} 


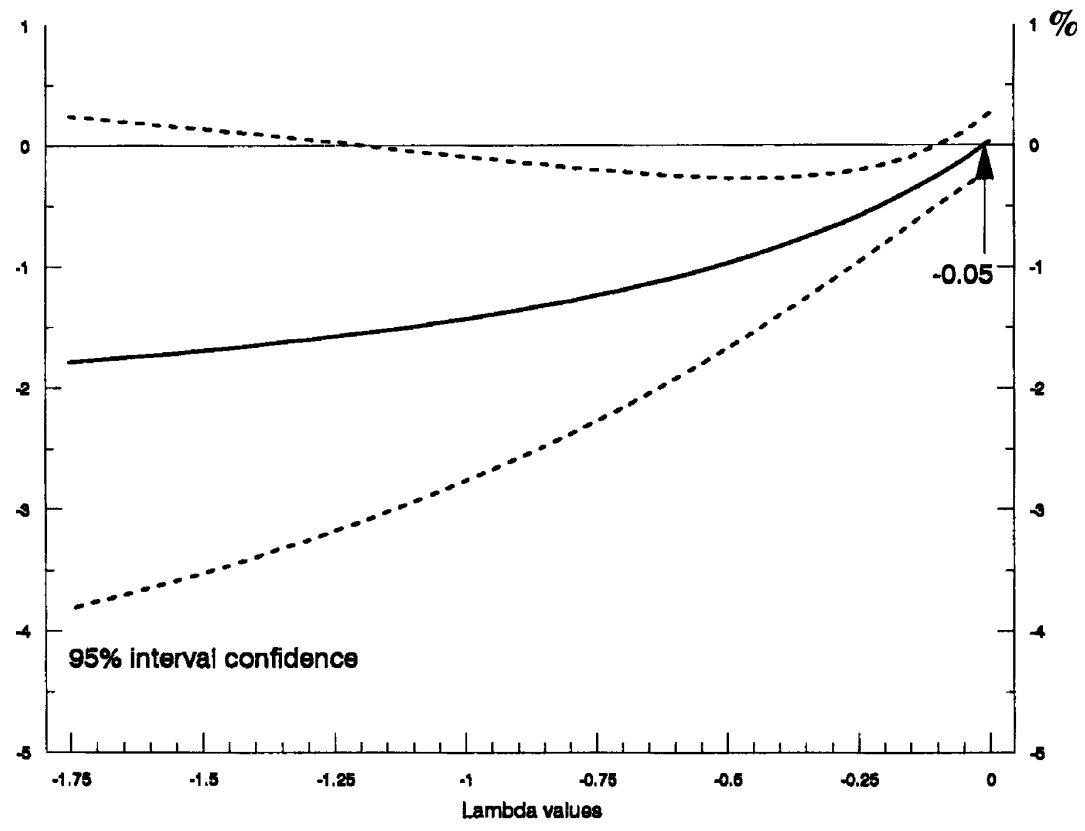

Fig. 6. Responses to an interest rate shock Monetarist identification with interset rates in the VAR

Table 4. Sacrifice ratios for a $1 \mathrm{p} \mathrm{p}$ permanent reduction in inflation rate (trivariate model including short-run interest rates) (1982-1997)

\begin{tabular}{|c|c|c|}
\hline Horizon & $u$ & SR \\
\hline 4 & 004 & 004 \\
\hline 8 & 016 & 020 \\
\hline 12 & 013 & 033 \\
\hline 16 & 013 & 046 \\
\hline$\infty$ & 013 & $\begin{array}{l}059 \\
11 \quad 115)\end{array}$ \\
\hline
\end{tabular}

Note: Bootstrap $90 \%$ confidence interval in parenthesis

sample period), yields a present value of $x /(\rho-0.025)$. If the costs in terms of output are permanent as it seems to be the case, then disinflation of 1 p.p. will be a worthy enterprise if $x>c$, where $c$ is the annual loss of GDP. According to the monetarist model, using an Okun's coefficient of 2.0 (see Dolado and López-Salido 1996), the threshold value in the first case of GDP is $0.24 \%$ of GDP per year (obtained, following Table 4, as 2 times 0.6 , divided by 5, since the sacrifice ratio is computed every 5 years). Dolado et al. (1999) estimate that the permanent benefits are about $0.7 \%$ of GDP per year and, hence, conclude that achieving price stability seems a worthy enterprise.

Finally, we would like to comment briefly on how our results, based upon the SVAR methodology, compare to the more traditional ones obtained under the estimation of a simultaneous equations model. In this respect, Andrés et al. 
(1996) make use of a small quarterly macroeconometric model to compute the sacrifice ratio of permanently reducing inflation in Spain by 1 p.p. They conclude that these costs are about $0.45 \%$ of GDP per year on a permanent basis, which is slightly higher than what we find here. Equally, Ball (1996) suggests that a permanent reduction in inflation of 1 p.p. comes with a permanent annual output loss of about $0.55 \%$ of GDP, a figure again slightly higher than $0.24 \%$ estimated for the monetarist case in the trivariate VAR. Finally, Bullard and Keating (1995) find that, for Spain, permanent inflation (nominal) shocks have no statistically significant effect on GDP in the long-run, but their study excludes the recession in the early nineties.

\section{Conclusions}

In this paper, we have studied the joint dynamic behaviour of inflation and unemployment in the Spanish economy over the period 1964-1997, with the aim of documenting the existing trade-offs between both variables at high and low frequencies, and over several subperiods. We proceed in the style of King and Watson (1994), who used structural VAR techniques to undertake an identification of the Phillips curve System. We have used, in particular, three identification schemes which fit the data equally well, but that have different implications for the magnitude of Phillips trade-offs and for sacrifice ratios. A key assumption in our analysis is that both unemployment and inflation can be described as firstorder integrated processes - I(l)- for the sample period, therefore avoiding the Lucas-Sargent critique about the econometric estimation of "spurious" trade-offs (Lucas and Sargent 1979).

As regards the different identification outlines, the following results stand out. A traditional keynesian scheme yields: (i) a large estimated long-run tradeoff between inflation and unemployment of around -0.6; (ii) the short-run (one year) and long-run variability of unemployment is almost completely explained by demand shocks which, in turn, only explain $12 \%$ of the variability of inflation at all frequencies; and (iii) the sacrifice ratio over five years is estimated to be a cumulative rise of 2.5 p.p. in unemployment for a permanent disinflation of 1 p.p. By contrast, a monetarist interpretation yields: (i) a long-run trade-off of -0.3 , half of that estimated under the keynesian scheme; (ii) demand shocks explain almost $90 \%$ of inflation variability and $15 \%$ of unemployment variability; and (iii) a sacrifice ratio of about 1.3. Finally, an alternative real business-cycle outline yields: (i) negligible trade-off; (ii) unemployment variability is almost fully explained by supply shocks whereas $90 \%$ of inflation variability in the shortrun, and $60 \%$ in the long-run, is due to demand shocks; and (iii) a negligible sacrifice ratio.

With regard to the analysis of different subsamples, we find that the results for the total sample are seemingly dominated by the behaviour during the 1979-1997 subsample, whereas the shifts in the Phillips curve before the end of the 1970s were dominated by supply shocks. Next, on the basis of extraneous information, 
we analyze the contribution of demand and supply shocks to the variability of inflation and unemployment over significant episodes in the recent disinflationary period in Spain, finding that the monetarist scheme fits better with prior beliefs. Finally, several robustness exercises have been undertaken. In particular, augmenting the bivariate VAR with a third variable (a short-term interest rate), in order to disentangle monetary from "non-monetary" shocks, indicates that the unemployment-inflation trade-off remains permanent though about one-half of what is estimated in the bivariate VAR, in agreement with the high degree of hysteresis in the Spanish labor market. Nonetheless, the benefits stemming from lower inflation, needed to overcome the estimated costs, are higher in both cases.

\section{References}

Andrés, J (1991) Persistencia del Paro Moneda y Crédito 197:91-127

Andrés, J, Mestre, R, Vallés, J (1997) The Transmission Mechanism of Monetary Policy in Spain In: Malo de Molina, J L, Gutierrez, F, Viñals, J (eds) Monetarv Policy and Inflation in Spain McMillan, London, Chapter 20

Andrews, D W K (1993) Test of Parameter Instability and the Structural Change with Unknown Change Point Econometrica 61:821-856

Ball, L (1996) Disinflation and the NAIRU NBER Working Paper 5520

Barro, R , Rush, M (1980) Unanticipated Money and Economic Activity In: Fischer, S (ed ) Rational Exvectations and Economic Policy University of Chicago Press, Chicago, IL

Bentolila, S , J Dolado (1994): "Labour Flexibility and Wages: Lessons from Spain", Economic Policy, 18, 53-99

Blanchard, O J, Quah, D (1989): The Dynamic Effects of Aggregate Demand and Supply Disturbances American Economic Review 79(4):656-673

Blanchard, O J, Jimeno, JF (1995) Structural unemployment: Spain versus Portugal American Economic Review, Papers and Proceedings 85(2):212-218

Bullard, J , Keating, J (1995) The Long-Run Relationship Between Inflation and Output in Post-War Economies Journal of Monetary Economics 36:477-496

Christiano, L, Eichenbaum, M , Evans, C (1995) Identification and the Effects of Monetary Policy Shocks In: Blejer, M, Eckstein, Z, Hercowitz, Z, Leiderman, L (eds ) Financial Factors in Economic Stabilization and Growth University of Chicago Press, Chicago

Dolado, J (1984) Neutralidad Monetaria y Expectativas Rationales: Alguna evidencia para el caso español Revista Española de Economía 1:77-89

Dolado, J J , López-Salido, J D (1996) Hysteresis and Economic Fluctuations: Spain 1970-1994 CEPR WP 1334

Dolado, J J , Jimeno, J F (1996) The Causes of Spanish Unemployment: A Structural VAR Approach European Economic Review 41:1281-1307

Dolado, J , González-Páramo, J M , Viñals, J (1999) A Cost-Benefit Analysis of Going from Low Inflation to Price Stability in Spain In: Feldstein, $\mathrm{M}$ (ed ) The Costs and Benefits of Achieving Price Stability University of Chicago Press, Chicago

Escrivá, J L, Santos R (1991) Un estudio del cambio de regimen en la variable instrumental del control monetario en España Sevicio de Estudios Documento de Trabajo 9111

Espasa, A, Cancelo, J (1993) Métodos Cuantitativos para el análisis de la coyuntura económica Alianza Editorial, Madrid

Evans, G (1994) Comments on 'The Post-War Phillips Curve: A Revisionist Econometric History' Carnegie Rochester Conference Series on Public Policy 41:219-223

Feldstein, M (1999) The Costs and Benefits of Going from Low Inflation to Price Stability In: Feldstein, M (ed ) The Costs and Benefits of Achieving Price Stability University of Chicago Press, Chicago

Gordon, R J (1970) The Recent Acceleration of Inflation and Its Lessons for the Future Brookings Papers on Economic Activity 1:8-41 
Gordon, R.J. (1990) What is New Keynesian Economics? Journal of Economic Literature 28:11161171

King, R.G., Watson, M.W. (1994) The Post-War Phillips Curve: A Revisionist Econometric History. Carnegie Rochester Conference Series on Public Policy 41:157-219

Layard, R., Nickell, S., Jackman R. (1991) Unemployment: Macroeconomic Performance and the Labour Market. Oxford University Press, Oxford

Leeper, E., Sims, C., Zha, T. (1996) What Does Monetary Policy Do? Brookings Papers on Economic Activity 2:1-77

Lucas, R.E. (1972a) Econometric Testing of the Natural Rate Hypothesis. In: Eckstein, 0. (ed.) The Econometrics of Price Determination. Board of Governors of the Federal Reserve System, Washington, D.C

Lucas, R.E. (1972b) Expectations and the Neutrality of Money. Journal of Economic Theory 4:103124

Lucas, R.E., Sargent, T.J. (1979) After Keynesian Macroeconometrics. In: Lucas, R. (ed.) After the Phillips Curve: Persistence of High Inflation and Unemployment, Federal Reserve Bank of Boston, Conference Series No. 19

Manning, A. (1993) Wage Bargaining and the Phillips curve: The Identification and Specification of Aggregate Wage Equations. Economic Journal 103(416):98-118

Roberts, J. (1993) The Sources of Business Cycles: A Monetarist Interpretation. International Economic Review 34(4):923-934

Sargent, T.J. (1982) The Ends of Four Big Inflations. In: Sargent, T., Hall, R. (eds.) Inflation: Causes and Effects. NBER and the University of Chicago, Chicago 